\title{
La ausencia de los dioses taínos. Sobre el fracaso hermenéutico de la obra de Ramón Pané
}

\author{
Sergio Botta*
}

Resumen: La Relación acerca de las antigüedades de los indios de Ramón Pané constituye el primer registro de carácter etnográfico, después del contacto de los europeos con el continente americano. En esta obra se produce un primer intento de descripción y comprensión de la religiosidad de los pueblos indígenas del Caribe. Este artículo trata de analizar la voluntad de Pané por reubicar esta religiosidad dentro de un modelo conceptual conocido y, al mismo tiempo, observa el fracaso hermenéutico de su proyecto.

Palabras Clave: Ramón Pané, Cristóbal Colón, Taínos, Idolatría, Dioses, Cemíes.

ABSTRAC: The Relación acerca de las antigüedades de los indios by Ramón Pané represents the first ethnographic record after the first European contact with the Americas. It is also the first attempt to describe and understand the indigenous religion of the Caribbean peoples. This article analyzes the effort made by Pané to introduce this different kind of religiosity within a recognized conceptual model and, at the same time, pays attention to the hermeneutic failure of his project.

Key words: Ramón Pané, Christopher Columbus, Taino, Idolatry, Gods, Cemís. 


\section{INTRODUCCIÓN}

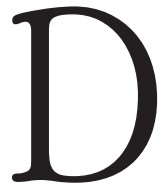

urante el primer viaje al Nuevo Mundo, Cristóbal Colón entró en contacto con los pueblos indígenas del Caribe. ${ }^{1}$ Los taínos fueron una de las primeras muestras de la diversidad del continente americano $^{2}$ que la civilización europea encontró a principios de su historia colonial. ${ }^{3}$ Es comprensible, pues, que las expectativas y los deseos del Viejo Mundo hayan influido en los procesos de representación de la alteridad cultural al comienzo de la época de los descubrimientos geográficos. ${ }^{4}$ Esto es particularmente evidente en lo que respecta a las primeras descripciones de la dimensión religiosa de los taínos. No olvidemos que la religión, como código primario del pensamiento y de las prácticas sociales del Viejo Mundo, había dominado, durante la Edad Media, el ámbito público y privado de la vida europea y orientó también las relaciones entre culturas en la época del contacto con el Nuevo Mundo. ${ }^{5}$

1 En este contexto no será posible abordar el problema de la biografía de Colón, debido a la enorme cantidad de fuentes documentales que se le dedican. Nos limitaremos a indicar algunas obras críticas útiles para contextualizar nuestra perspectiva. Véase Antonello Gerbi, $L a$ natura delle Indie Nove: da Cristoforo Colombo a Gonzalo Fernández de Oviedo, MilanoNapoli, Ricciardi, 1975; Stephen Greenblatt, Marvellous Possessions: The Wonder of the New World, Oxford, Oxford University Press, 1991; Peter Hulme, Colonial Encounters: Europe and the Native Caribbean, 1492-1797, Londres, Routledge, 1986; Tzvetan Todorov, La conquête de l'Amérique. La question de l'autre, París, Éditions du Seuil, 1982.

2 Por supuesto, los taínos representan solamente una parte de la extraordinaria complejidad étnica y cultural del Caribe a la llegada de los españoles. Para una introducción a la pluralidad indígena de esta área, véase William F. Keegan, The People Who Discovered Columbus: The Prehistory of the Bahamas, Gainesville, University Press of Florida, 1992.

3 Sobre la cultura taína, véanse, entre muchos otros, los trabajos de William F. Keegan, Taíno Indian Myth and Practice: the Arrival of the Stranger King, Gainesville, University Press of Florida, 2007; Irving Rouse, The Tainos: Rise and Decline of the People who greeted Columbus, New Haven, Yale University Press, 1992.

4 Para una nueva perspectiva en el estudio de las relaciones globales en la Edad Moderna, véase Charles H. Parker, Global Interactions in the Early Modern Age, Cambridge, Cambridge University Press, 2010.

5 Para una historia del estudio científico de la religión como proceso histórico desarrollado en la primera Edad Moderna, véanse Philippe Borgeaud, Aux origines de l'bistoire des religions, París, Seuil, 2004, e Ivan Strenski, Thinking about Religion. An Historical Introduction to Theories of Religion, Oxford, Blackwell, 2006. 
Desde el primer encuentro, la mirada de Colón respecto de los taínos resulta opaca, dominada por categorías cognitivas medievales e incapaz de retomar aquellos elementos de interés etnográfico que habrían permitido una reconstrucción fidedigna de la religión de los pueblos de las Antillas. ${ }^{6}$ Si bien ésta aparece hoy en gran medida irrealizable (salvo, quizá, a través de la arqueología), ${ }^{7}$ las fuentes documentales colombinas resultan de capital importancia para rescatar los discursos sobre la religión al comienzo de la Edad Moderna. No obstante su limitada capacidad de comprensión de la diversidad cultural, los discursos colombinos abrieron una reflexión sobre la pluralidad de los sistemas religiosos que produjo, en el espacio de unas pocas décadas, la aparición de una "nueva ciencia": la historia de las religiones. ${ }^{8}$

Desde el primer momento, los protagonistas de la exploración del Caribe mostraron grandes dificultades para comprender la "inusitada" religiosidad indígena. Al igual que los demás aspectos de las culturas indígenas, la religión de los taínos fue representada por medio de una "retórica de la ausencia" que le permitió al Almirante describir a los pueblos del Caribe a través de una serie de términos con connotaciones negativas o que aludían a supuestos defectos. ${ }^{9}$ Desde el 12 de octubre de 1492, la imagen de la desnudez indígena dominó el sistema retórico de la descripción colombina, operando como una especie de metáfora ${ }^{10}$ para expresar lo que se percibía como el "vacío cultural" de los pueblos indígenas:

6 Para un análisis de la influencia del pensamiento "medieval" en la mentalidad de Colón, véase Todorov, op. cit.

7 En esta perspectiva, nos parece fundamental la propuesta metodológica de José R. Oliver, Caciques and Cemi Idols. The Web Spun by Taino Rulers between Hispaniola and Puerto Rico, Tuscaloosa, University of Alabama Press, 2009.

8 Guy G. Stroumsa, A New Science. The Discovery of Religion in the Age of Reason, CambridgeLondres, Harvard University Press, 2010, p. 15.

9 Sobre este tema, véanse, por ejemplo, las reflexiones sobre una "retórica de la ausencia" de Tzvetan Todorov, Nous et les autres. La réflexion française sur la diversité bumaine, París, Éditions du Seuil, 1989.

${ }^{10}$ En esta perspectiva, he trabajado sobre el tema de la desnudez en Sergio Botta, La nudità deglialtri. Storia delle religioni, sguardo europeo, corpi indigeni, Roma, Bulzoni [en prensa]. 
Ellos andan todos desnudos como su madre los parió, y también las mugeres, aunque no vide más de una fartomoça, y todos los que yo vi eran todos mançebos, que nungunovide de edad de más de XXX años, muy bien hechos, de muy fermosos cuerpos y muy buenas caras, los cabello gruessos cuasi como sedas de cola de caballos y cortos. Los cabellos traen ençima de las çejas, salvo unos pocos detrás que traen largos, que jamás cortan. D'ellos se pintan de prieto, y d'ellos son de la color de los canarios, ni negros ni blancos [...]. Ellos no traen armas ni las cognosçen, porque les amostré espadas y las tomavan por el filo y se cortavan con ignorançia. ${ }^{11}$

Si a la desnudez física correspondía también una simétrica ignorancia racional, ésta podía ser considerada "aceptable" ya que representaba a los indígenas de una manera "positiva", es decir, a través de la puesta en escena de una corporeidad agradable y armoniosa. Por supuesto, este lado positivo se expresaba sólo con la condición de simbolizar la mansedumbre de los indígenas, su falta de agresividad y su supuesta natural propensión para ser dominados. En esta perspectiva, la lista de connotaciones defectuosas proporcionada por Colón se incrementó dramáticamente ya en las primeras páginas del Diario: los taínos son "gente muy pobre de todo", "sin armas y sin ley", 13 pero, sobre todo, el Almirante cree que "ligeramente se harían cristianos, que me pareció que ninguna secta tenían". ${ }^{14}$

Aunque es evidente que la "desnudez ontológica" de los taínos no describe o identifica una verdadera diferencia cultural, en el texto colombino representa la señal de su exclusión de la vida racional y política. Como resultado, su recuperación sólo es posible siempre y cuando los indígenas muestren una completa aceptación de la tutela europea. En este marco conceptual, la ausencia de una religión en los pueblos del Caribe es el producto de un discurso colonial que procura entregar a los soberanos católicos la imagen de una conquista factible

${ }^{11}$ Cristóbal Colón, Diario del Primer Viaje, en Consuelo Varela y Juan Gil [eds.], Textos y documentos completos, 2a ed., Madrid, Alianza Editorial, 1992, pp. 110 y 111.

${ }^{12}$ Loc. cit.

${ }^{13}$ Ibid., p. 131.

${ }^{14}$ Ibid., p. 111. 
que no encontrará resistencias ni obstáculos. ${ }^{15}$ Sin embargo, las estrategias retóricas que Colón utilizó para describir a los indígenas del Caribe y a sus sistemas religiosos habrían sido puestas en tela de juicio por el encuentro con la realidad empírica. ${ }^{16}$ Durante el primer viaje, se encuentran muchos indicios de la incapacidad del Almirante para entender los elementos contradictorios que aparecen frente a sus ojos. Detengámonos, por ejemplo, en la famosa descripción de un espacio sagrado que Colón encontró el 3 de diciembre de 1492:

Vide una casa hermosa no muy grande y de dos puertas, porque así son todas, y entré en ella y vide una obra maravillosa, como cámaras hechas por una cierta manera que no le sabría dezir, y colgado al çielo d'ella caracoles y otras cosas; yo pensé que era templo, y los llamé y dixe por señas si hazían en ella oraçion; dixeron que no, y subió uno d'ellos arriba y me dava todo cuanto allí avía, y d'ello tomé algo. ${ }^{17}$

Dos elementos de esta descripción presentan enorme interés histórico-religioso. El primero está representado por la tentativa espontánea de insertar este edificio (en un principio definido como "casa") en una elemental grilla conceptual, ${ }^{18}$ que permitiría reconocer a un templo en cada espacio sagrado (un edificio dedicado al culto) y, en consecuencia, le consentiría considerarlo como un lugar para rezar. En segundo lugar, es posible apreciar un revelador cortocircuito conceptual cuando Colón no parece conocer las palabras adecuadas ("por

${ }^{15}$ Sobre Colón y la construcción de un discurso colonial, véase Beatriz Pastor, Discurso narrativo de la Conquista de América, La Habana, Ediciones Casa de las Américas, 1983. Para una teoría del discurso colonial en las Américas, véanse, por ejemplo, las reflexiones críticas de Rolena Adorno, "Reconsidering Colonial Discourse for Sixteenth and Seventeenth-Century Spanish America", en Latin American Research Review, vol. 28, núm. 3, 1993, pp. 135-145 y Walter D. Mignolo, "Colonial and Postcolonial Discourse: Cultural Critique or Academic Colonialism?", en Latin American Research Review, vol. 28, núm. 3, 1993, pp. 120-134.

${ }^{16}$ Por supuesto, la historia del texto colombino y de las interpolaciones lascasianas es muy compleja. En este contexto no podemos, por ende, proporcionar un análisis profundo de las estrategias retóricas del Diario. Véase al respecto Margarita Zamora, Reading Columbus, Berkeley-Los Ángeles, University of California Press, 1993.

17 Colón, op. cit., pp. 151-152.

${ }^{18}$ Sobre esta noción de grille conceptuelle, véase Carmen Bernand, Serge Gruzinski, De l'idolâtrie: une archéologie des sciences religieuses, París, Editions du Seuil, 1988. 
una cierta manera que no le sabría dezir") para describir la naturaleza y la función del edificio. Se trata de un "silencio conceptual" que representa la señal de una confusión hermenéutica que sólo puede fluctuar entre el reconocimiento de la "hermosura" del edificio (una función "estética") y la pregunta acerca de su función (que el Almirante sospechaba de carácter religioso). ${ }^{19}$

Es por esta razón que la crónica del fraile jerónimo Ramón Pané representa, por voluntad misma del Almirante, un intento de proporcionar una respuesta a estas preguntas acerca de la naturaleza de la vida religiosa de los pueblos del Caribe. Colón creía, pues, que era necesario nombrar a un religioso para tratar de entender si los taínos vivían sin religión, como le había parecido durante el primer viaje, o si por el contrario se encontraban entre ellos claros signos de idolatría.

Idolatría u otra secta no he podido conocerles, aunque todos sus reyes, que son muchos, tanto en la Española como en todas las demás islas y en Tierra Firme, tienen una casa para cada uno de ellos, separada de la población, en la cual no hay otra cosa sino imágenes de madera, labradas en relieve, que ellos llaman cemíes, ni en esa casa se trabaja para otro efecto o servicio sino para estos cemíes, con cierta ceremonia y oración, que van a hacer allí, como nosotros a la iglesia. ${ }^{20}$

En este exordio de la carta, hoy perdida, que acompañaba la obra de Pané, se expresan todas las dudas del Almirante que, a pesar de la hipótesis de la ausencia de idolatría entre los taínos (interpretación esencial para ofrecer una representación de los indígenas que justificara su dominio), se mostraba consciente de la presencia de numerosos elementos culturales indígenas que ponían en tela de juicio su personal interpretación de la religión. Esto se hace evidente,

19 "Hallaron muchas estatuas en figuras de mugeres y muchas cabeças en manera de cara[n]tona, muy bien labradas. No sé si esto tienen por hermosura o adoran en ellas", Colón, op. cit., p. 127. Nos parece interesante también la reflexión de Giuseppe A. Samonà, "Linsaisissable religion des Taïnos. Esquisse d'anthropologie historique", en Journal de la société des américanistes, vol. 89, núm. 2, 2003, p. 14.

${ }^{20}$ Cristóbal Colón, Palabras del Almirante [ca. 1496], en Ramón Pané, Relación acerca de las antigüedades de los Indios (nueva versión con notas, mapa y apéndices), edición de José Juan Arrom, México, Siglo Xxi, 1974, p. 88. 
por ejemplo, cuando Colón menciona las creencias en los cemíes, la presencia de rituales comunitarios, las huellas de una religión relacionada con el poder político y, finalmente, los signos de una reflexión en torno al destino post mórtem de los seres vivos. Estas dudas, que anticipan las preguntas de una disciplina que será la historia comparada de las religiones, fueron entregadas por Colón en las manos de un humilde fraile jerónimo.

\section{LA OBRA DE PANÉ COMO PRIMERA ETNOGRAFía AMERICANA}

En la elaborada preparación del segundo viaje, para el cual poseía recursos económicos superiores al primero, el Almirante tuvo también la oportunidad de establecer una base sólida para la obra de evangelización de La Española, como parte de las tareas que le fueron encomendadas por la Corona. Este trabajo fue asignado al fraile catalán Bernat Boil, quien estaba a cargo de una docena de religiosos, entre los cuales se encontraba Pané. ${ }^{21}$ Salido de Cádiz el 25 de septiembre de 1493, el fraile jerónimo llegó a La Isabela en noviembre del mismo año y desde allí fue enviado al interior de la isla para estudiar en detalle el idioma, las costumbres y las tradiciones de los indígenas. En los años siguientes, Pané tuvo la oportunidad de experimentar de manera directa la forma de vida de los taínos; primero, aprendiendo la lengua que se hablaba en la zona de Macorí (una variante menor de los idiomas que se utilizaban en la isla) y, en segundo lugar, adquiriendo un amplio conocimiento de las variantes lingüísticas más difundidas en la isla, gracias a una prolongada estancia en el territorio del cacique Guarionex.

Como resultado de su contacto directo con los pueblos indígenas, Pané supo elaborar la descripción más detallada de la religión indígena que se haya producido por lo menos hasta mediados del siglo xvi, cuando en la Nueva España la obra de los franciscanos dio lugar a un trabajo etnográfico de enormes proporciones. A pesar de que en este contexto no es posible extenderse acerca de

${ }^{21}$ Para una biografía del fraile jerónimo y también para una edición crítica del texto italiano, véase Ramón Pané, Le antichità degli indiani, introd., notas y glosario de Roberta Pieraccioli y Maurizio Rippa Bonati, Cinisello Balsamo (Milano), Edizioni Paoline, 1992. 
los acontecimientos biográficos del fraile, es preciso mencionar que Pané comenzó a escribir su informe en 1496 y que la obra fue concluida entre 1498 y 1500. De todos los religiosos que trabajaron en el Nuevo Mundo durante el segundo viaje de Colón, Pané fue el único que dejó un informe completo, el cual constituye la fuente misionera más antigua de la primera etapa de la exploración del continente americano. La Relación se configura entonces como un documento de excepcional importancia: mientras que es una fuente de menor trascendencia desde el punto de vista de los conocimientos geográficos y políticos, reviste un papel único para el conocimiento de la religión de las poblaciones del Caribe. Además, su interés no se limita solamente a la dimensión religiosa; de hecho, es la primera crónica de carácter monográfico disponible para la investigación americanista, y por esta razón puede ser concebida como una especie de "laboratorio" en el que nacieron y se desarrollaron muchos de los problemas relativos a la producción de fuentes documentales relacionadas con el conocimiento de las culturas indígenas. ${ }^{22}$

La historia de la obra de Pané es extremadamente compleja. El manuscrito original de la Relación está perdido; la versión más cercana al original es la transcrita por Fernando Colón en sus Historie, obra compuesta sin duda antes de su muerte en 1539. Por otro lado, también el camino de la obra de Fernando es considerablemente complicado, ya que sólo poseemos una traducción italiana publicada en Venecia en 1571 por Alfonso de Ulloa. ${ }^{23}$ El contenido de la Relación acerca de las antigüedades de los indios de Pané (obra definida en la versión italiana como Scrittura delle antichità de gl'Indiani) ${ }^{24}$ se conoce en su forma

${ }^{22}$ Véase Lewis Hanke, "The Dawn of Conscience in America: Spanish Experiments and Experiences with Indians in the New World", en Proceedings of the American Philosophical Society, vol. 107, núm. 2, 1963.

${ }^{23}$ Fernando Colombo, Historie del S.D. Fernando Colombo; Nelle quali s'ha particolare, et vera relazione della vita, et de' fatti dell'Ammiraglio D. Christophoro Colombo, suo padre..., trad. de S. Alfonso Ulloa, Venecia, Francesco de' Franceschi Sanese, 1571.

${ }^{24}$ Utilizamos aquí, para facilitar al lector de la lengua castellana, la versión publicada por José Juan Arrom (Pané, Relación acerca de las antigüedades de los indios), aunque sería necesaria, para elaborar análisis filológicos más profundos, una cuidadosa comparación con el texto italiano de 1571. 
más completa a través de la traducción de la obra de Fernando, quien parece haberla copiado con suficiente cuidado; de hecho, el hijo del Almirante mantuvo la escritura en primera persona del fraile catalán, lo que permitió limitar sus intervenciones directas en el texto.

Sin embargo, la Relación no fue traducida en forma igualmente precisa por Ulloa, que nos devuelve un texto corrompido, lo cual se manifiesta en las transcripciones de los términos en la lengua indígena. Por fortuna, es posible comparar el texto italiano con otras versiones producidas durante la primera parte del siglo xvi, aunque algunas de ellas están incompletas. ${ }^{25}$ Sabemos que el trabajo de Pané tuvo gran éxito y experimentó una rápida circulación en Europa. La popularidad de la Relación en los primeros años del siglo xvI parece haberse debido al interés causado por las primeras noticias exóticas que llegaron al Viejo Mundo sobre las poblaciones de las Indias. La obra de Pané fue leída, traducida y resumida en numerosas ocasiones por algunos de los más importantes protagonistas de la historia cultural europea. Entre las versiones del siglo xvi se destaca la traducción latina de Pedro Mártir de Anglería (quien propuso una traducción parcial en la primera de sus Décadas), y la versión castellana de Bartolomé de las Casas (quien utilizó algunos pasajes de la obra de Pané en su Apologética Historia). De menor peso, aunque importantes para la comprensión del texto de Pané, son también las versiones italianas de Giovanni Battista Ramusio, Angelo Trevisan, Giovanni Strozzi y Andrea Navagero. ${ }^{26}$

\section{La grilla CONCEPTUAl de Pané}

Más allá de los derroteros materiales de la Relación de Pané, volvamos a ella para dar cuenta de la importancia decisiva para la reconstrucción de los discursos re-

25 Sobre la difusión de la obra de Pané, véase, por ejemplo, Laura Laurencich Minelli, "Diffusione e censura nell'Italia cinquecentesca dell'opera di Fra' Ramón Pané”, en L'Universo, núm. 1, 1991 (Atti del simposio "Gli indios di Hispaniola e la prima colonizzazione europea in America"), pp. 60-67.

${ }^{26}$ Véase Roberta Pieraccioli, Maurizio Rippa Bonati, "Introduzione", en Pané, Le antichità degli indiani..., pp. 7-74. 
ligiosos de la primera Edad Moderna. Aunque no es posible aquí detenerse en las características proto-etnográficas de esta relación, sí es posible afirmar que la falta de familiaridad de los europeos con las culturas indígenas en ese momento de la historia obligó a Pané a redactar un texto algo ingenuo, confuso en su estructura argumentativa y privado de cualquier posible confrontación con otras fuentes contemporáneas dedicadas al mismo tema. No nos interesa, sin embargo, investigar en detalle la capacidad de proporcionar una descripción etnográfica de la cultura taína, sino más bien analizar el valor religioso e histórico de su obra; es decir, su contribución, ya sea voluntaria o involuntaria, a la construcción de la primera etapa del discurso occidental sobre la religiosidad indígena. ${ }^{27}$

En este sentido, resulta más fructífero observar los límites del proyecto hermenéutico de la Relación de Pané. Por otra parte, fue el mismo fraile catalán quien mostró sus dificultades en la comprensión del universo religioso indígena. Esto se manifiesta, por ejemplo, en su incapacidad para ofrecer algún tipo de explicación de los ricos relatos míticos recopilados en su crónica. A menudo, Pané describe los elementos religiosos de los taínos como ridículas supersticiones o engaños: elementos que aparecen impenetrables para la mentalidad religiosa europea, a razón de la falta de escritura y libros, que en el pensamiento occidental representan la forma natural de expresión de la religión: la Sagrada Escritura. Las continuas manifestaciones de asombro y desconcierto de Pané son, sin duda, la señal de su simplicidad teológica, que fue notada por el mismo Las Casas:

Dice más el Almirante: que había trabajado de saber si tenían las gentes de esta Isla secta alguna que oliese a clara idolatría, y que no lo había podido comprehender, y que por esta causa había mandado a un catalán que había tomado hábito de ermitaño, y le llamaban fray Ramón, hombre simple y de buena intención, que sabía algo de la lengua de los indios, que inquiriese todo lo que más pudiese saber de los ritos y religión y antigüedades de las gentes de esta isla y las pusiese por escripto. Este fray Ramón escudriñó lo que pudo, según lo que alcanzó de las

${ }^{27}$ Véase, por ejemplo, Laura Laurencich Minelli, "Fra' Ramón Pané e la fortuna della sua opera sulla religione precolombiana dell'Hispaniola”, en Rivista di Storia e Letteratura Religiosa, vol. XXVI, núm. 2, 1990, pp. 229-241. 
lenguas, que fueron tres las que había en esta Isla; pero no supo sino la una de una chica provincia que arriba dejimos llamarse Macorix de abajo, y aquélla no perfectamente, y de la universal supo no mucho. ${ }^{28}$

Por otro lado, el malestar de Pané frente a la religión taína no sólo se manifiesta en algunos mal entendidos, sino que, a pesar de su "buena intención", se presenta continuamente en toda la Relación y muestra el fracaso de su entero proyecto hermenéutico. Contrariamente a lo que se podría creer, desde el punto de vista cristiano, la atención a los detalles, la gran cantidad de términos en lengua indígena y la escasez de comentarios por parte del autor (aunque puedan parecer útiles para una reconstrucción etnográfica) muestran la excesiva "simplicidad" del fraile (de la cual con razón se quejó Las Casas), y su incapacidad para esbozar una primera explicación "cristiana" de la irreductibilidad de los elementos religiosos indígenas.

De hecho, la desordenada colección de los datos etnográficos se encuentra varias veces en conflicto con la propuesta de un proyecto sistemático que el fraile busca plantear, sin éxito, en el exordio de su obra. En las primeras páginas de la Relación, Pané esboza los confines de un modelo hermenéutico que intenta utilizar para dar forma coherente a la exposición del material recogido en La Española:

Yo, fray Ramón, pobre ermitaño de la Orden de San Jerónimo, por mandato del ilustre señor Almirante y virrey y gobernador de las Islas y de la Tierra Firme de las Indias, escribo lo que he podido aprender y saber de las creencias e idolatrías de los indios, y de cómo veneran a sus dioses. De lo cual ahora trataré en la presente relación. ${ }^{29}$

${ }^{28}$ Bartolomé de las Casas, Apologética Historia, ed. de J. Pérez de Tudela Bueso, Madrid, Atlas, 1958, p. 417.

29 Pané, Relación..., p. 21. El texto en italiano dice lo siguiente: "Io frate Roman, povero Eremita dell'ordine di San Gieronimo, per comandamento dello Illustre Signor lo Ammiraglio, et vice Re, et Governatore dell'Isole, et della terra ferma delle Indie, scrivo quel, che ho potuto apprendere, et saper della credenza, et idolatria, degl'Indiani, et come osserva i loro Dei. Di che hora io tratterò nella presente scrittura", Pané, Le antichità degli indiani..., p. 116. 
Contrariamente a lo que había notado Las Casas, Pané se muestra consciente de la necesidad de un modelo conceptual que organice los materiales indígenas. Si nos fijamos en la sintética grilla conceptual proporcionada por el jerónimo, podemos notar su menor complejidad respecto a la que más tarde sería propuesta por Las Casas para describir las religiones indígenas de América. ${ }^{30}$ Sin embargo, esto no significa que Pané no reconozca la necesidad de ubicar las creencias y la idolatría de los indígenas dentro de una categoría de carácter "intercultural": la veneración de los dioses.

En un primer nivel de lectura, entonces, es evidente que se trata de un intento de generalizar las prioridades del cristianismo y de encontrar sus huellas (que, sin embargo, se expresan entre los taínos como formas de idolatría) también en las culturas indígenas. Si bien sólo en el cristianismo es posible inscribir la correcta adoración del Dios único, Pané busca averiguar si existen entre los taínos huellas de cultos idolátricos y de veneraciones de diferentes deidades, para colocar así a los indígenas en la categoría comparativa de los pueblos "paganos", es decir, de todos aquellos pueblos de la antigüedad que tenían como forma religiosa natural la veneración de múltiples dioses. ${ }^{31}$

Es evidente que Pané no entendía, o quizá no era capaz de utilizar un vocabulario "clásico" para recuperar las imágenes de los dioses de los "antiguos", con el objetivo sistemático de "traducir" las inauditas "veneraciones" de los taínos. Por otra parte, cabe hacer notar que esta metodología comparativa tardaría algunas décadas antes de ser utilizada puntualmente, por ejemplo, en la obra del mismo Las Casas. Es preciso evitar caer entonces en una lectura anacrónica: una "teoría del politeísmo" 32 no existía a principios del siglo xvI, y se desarrolló completamente sólo al final de un largo siglo de relaciones interculturales que

${ }^{30}$ Véase Gruzinski, op. cit.

31 Sobre la comparación entre el Nuevo Mundo y los antiguos, véase, por ejemplo, Sabine MacCormack, "Gods, Demons, and Idols in the Andes", en Journal of the History of Ideas, núm. 67, 2006, pp. 623-647.

32 Véase, en esta perspectiva, Sergio Botta, "Towards a Missionary Theory of Polytheism: The Franciscans in the Face of the Indigenous Religions of New Spain", en Id., Mamufacturing Otherness. Missions and Indigenous Cultures in Latin America, Newcastle Upon Thyne, Cambridge Scholars Press, 2013, pp. 11-35. 
la civilización europea había establecido no sólo en el Nuevo Mundo, sino también en un contexto global más amplio. ${ }^{33}$

En esta perspectiva, el trabajo de Pané es de importancia decisiva: si representa la primera etnografía religiosa de las Américas, su exordio programático muestra cómo todo el discurso acerca de las religiones indígenas se expresará en los términos de una reflexión sobre la naturaleza de las divinidades, o más bien, sobre la relación conceptual entre la "correcta" veneración del Dios único y la difusión universal de la idolátrica veneración de infinitas divinidades. ${ }^{34}$ En este sentido, la Relación constituye una contribución fundamental para la reconstrucción del discurso sobre las religiones del Nuevo Mundo, ya que se observa en ella el principio de un proceso de circulación de bienes culturales que, en la época de los descubrimientos geográficos, fueron utilizados por los cronistas europeos para favorecer una forma de inclusión "conceptual" de la pluralidad religiosa que aparecía en el curso de la Edad Moderna. Al mismo tiempo, entonces, mientras de un lado se procedía con el "exterminio" de las religiones reales, por el otro, era posible asimilarlas conceptualmente a través de una reflexión connotada en sentido cristiano.

Apuntalado lo anterior, podemos volver al texto de Pané para explicar las razones de aquel proceso que hemos definido como fracaso hermenéutico de la Relación. Si la veneración de los dioses era la piedra angular de todo el proyecto del fraile, y por ello debería haber servido para elaborar una coherente descripción de la religión indígena, llama la atención el hecho de que no exista huella alguna de divinidades indígenas en la obra entera de Pané. El mismo término "dioses", utilizado en el exordio programático, representa un bapax en la

33 Sobre el "descubrimiento" del politeísmo en la Edad de las Exploraciones geográficas, véase Francis Schmidt [ed.], Polytheisms: Degeneration or Progress? The Inconceivable Polytheism, Londres/París/Nueva York, Chur-Harwood, 1987, pp. 9-60.

34 Sobre el problema de la idolatría en la Edad Moderna véase Jonathan Sheehan, "Thinking about Idols in Early Modern Europe", en Journal of the History of Ideas, vol. 67, núm. 4, 2006, pp. 561-570; y Giuliano Gliozzi, "The Apostles in the New World: Monotheism and Idolatry between Revelation and Fetishism", en The Inconceivable Polytheism: Studies in Religious Historiograph, ed., por Francis Schmidt, Londres/París/Nueva York, Harwood Academic Publishers, 1987 (History and Anthropology, 3), pp. 123-148. 
Relación, ya que se encuentra en una única ocasión, en aquella cita puesta en el principio de la obra. Las esperadas huellas de un culto indígena a los dioses, que representaría la hipótesis interpretativa del trabajo de Pané, se diluyen por completo: "Cada uno, al adorar los ídolos que tienen en casa, llamados por ellos cemíes, observa un particular modo y superstición". 35

Después de haber propuesto a los dioses como axis del modelo interpretativo, Pané abandona esta ineficaz grilla conceptual y nos proporciona una "desordenada" descripción de la religión indígena (desordenada, por supuesto, desde el punto de vista cristiano, ya que en el orden narrativo el jerónimo no parece reconocer ningún elemento cristiano). Es evidente, por lo tanto, la razón por la cual esta descripción no puede ser aceptada por el dominico Las Casas, que, como veremos, buscará entre los indígenas rastros de una "religión natural". En la Relación, la descripción de Pané vuelve a utilizar el término "consolador" de "ídolo", al parecer más adecuado para expresar las críticas negativas y excluyentes hacia aquellas realidades religiosas, en este caso los cemíes, de las cuales los observadores europeos no entienden "modo y superstición":

Todos, o la mayor parte de los de la isla Española, tienen muchos cemíes de diversas suertes. Unos contienen los huesos de su padre, y de su madre, y parientes, y de sus antepasados; los cuales están hechos de piedra o de madera. Y de ambas clases tienen muchos; algunos que hablan, y otros que hacen nacer las cosas que comen, y otros que hacen llover, y otros que hacen soplar los vientos. Las cuales cosas creen aquellos simples ignorantes que hacen aquellos ídolos, o por hablar más propiamente, aquellos demonios, no teniendo conocimiento de nuestra santa fe. ${ }^{36}$

35 Pané, Relación..., p. 21. La cita en italiano es la siguiente: "Ciascuno nell'adorare gl'Idoli, che hanno in casa, da loro detti Cemini, osserva un particolar modo, e superstizione", en Pané, Le antichità..., p. 116.

36 Pané, Relación..., pp. 34 y 35. La cita en italiano es la siguiente: "Tutti, o la maggior parte di quell'Isola Spagnuola hanno molti Cemini di diverse sorti. Chi ha le ossa di suo padre, et di sua madre, et parenti, et de' suoi passati; i quali sono fatti di pietra, o di legno. Et di due sorti ne hanno molti; alcuni, che parlano; et altri, che fanno nascere le cose; et altri, che fanno piovere; et altri, che fanno soffiare i venti. Le quai cose credono quei semplici ignoranti che facciano quelli Idoli o, per parlare più propriamente, quei Demonij; non havendo eglino cognitione della nostra santa fede", Pané, Le antichità..., p. 131. 
Después de haber narrado algunos de los mitos de los taínos, en el capítulo XV de la Relación, Pané se acerca al problema central de su investigación, en el que sólo logra registrar las "diversas suertes" de los muchos cemíes venerados en La Española. Sin embargo, antes de proceder en el análisis de su proyecto hermenéutico, será útil observar brevemente esta lista de cemíes que Pané propone en la segunda parte de su obra.

\section{Los Cemíes de Pané}

Como se ha señalado anteriormente, el primer elemento que surge de las descripciones de Pané es la característica diversa de cemíes. Su forma, sus capacidades y sus funciones sagradas resultan tan diferentes, que se hace necesaria la recuperación de la terminología que había sido utilizada en el curso de cada confrontación del pensamiento cristiano contra las diferentes formas de paganismo. ${ }^{37}$ Los cemíes, que por un breve momento Pané había esperado poder comparar con los dioses de los antiguos, ahora vuelven a ser simples ídolos o incluso "demonios". De hecho, si el historiador de las religiones quisiera circunscribir la función y la naturaleza de los cemíes, de acuerdo a la lógica utilizada en la observación y análisis de las religiones politeístas, debería buscar campos de acción complejos pero coherentes; sin embargo, de las informaciones recogidas en el texto de Pané surgiría solamente un horizonte "confuso" que, por supuesto, no cumple con las reglas politeístas que esperarían los observadores europeos.

Como hemos señalado, según la obra de Pané los cemíes estaban hechos con partes de los cuerpos de los miembros de la familia o de los antepasados ("contienen los huesos de su padre, y de su madre, y parientes, y de sus antepasados"), pero también era posible construirlos a partir de materiales "artificiales" (piedra y madera); algunos de ellos tenían una clara agency (ya que son

37 Algo semejante se observa en la obra del franciscano Toribio de Benavente, Motolinía, en su primer intento de descripción de las idolatrías mesoamericanas. Al respecto, véase Sergio Botta, "El politeísmo como sistema de traducción. La obra misionera de Toribio de Benavente Motolinía frente a la alteridad religiosa de la Nueva España", en Guaraguao. Revista de Cultura Latinoamericana, vol. 28, núm. 12, 2008, pp. 9-26. 
capaces de hablar), ${ }^{38}$ mientras que otros controlaban los fenómenos meteorológicos y permitían el crecimiento de las plantas alimenticias. En la primera parte de la Relación, Pané también describe numerosos cemíes relacionados con lugares específicos, tales como cuevas, o incluso objetos celestes como el sol y la luna. ${ }^{39}$ Asimismo, hay cemíes que pertenecen a diferentes reinos de la naturaleza: los hay en forma animal (por ejemplo serpientes ${ }^{40} \mathrm{O}_{\text {perros }}{ }^{41}$ ) y en forma vegetal (como las raíces de la yuca). ${ }^{42}$ Por otro lado, uno de los elementos más singulares que emergen de las descripciones de Pané es la capacidad que tienen de cruzar la línea de separación entre el mundo de los vivos y el mundo de los muertos: vivos y muertos, por lo tanto, pueden habitar un mismo espacio, ser parte de un sistema cósmico coherente en el cual los seres no humanos, los humanos, los animales, las plantas y las fuerzas de la naturaleza comparten una misma dimensión física. Los cemíes cumplen también funciones diversas: establecen relaciones con las enfermedades y con las curas, pueden dominar la naturaleza y están vinculados con el ejercicio del poder.

38 Con el término agency se concibe la capacidad de un ser (humano y/o no-humano) de actuar en el mundo. Esta noción fue introducida en el léxico de las ciencias sociales por autores entre los cuales destacan Anthony Giddens, Central Problems in Social Theory: Actions, Structure and Contradiction in Social Analysis, Berkeley, University of California Press, 1992 y Pierre Bourdieu, Esquisse d'une théorie de la pratique précédé de Trois études d'ethnologie kabyle, Ginebra, Droz, 1972. A través de la noción de agency se quiere subrayar cómo las acciones de los seres sociales son dialécticamente vinculadas a las estructuras sociales, de manera que las dos dimensiones aparecen recíprocamente relacionadas. En esta perspectiva, más allá de la noción de libre albedrío, todas las acciones se consideran sujetas a las limitaciones de la vida social, cultural y lingüística.

39 Pané, Relación..., p. 31: "Y también dicen que el Sol y la Luna salieron de una cueva, que está en el país de un cacique llamado Mautiatihuel, la cual cueva se llama Iguanaboína, y ellos la tienen en mucha estimación, y la tienen toda pintada a su modo, sin figura alguna, con muchos follajes y otras cosas semejantes. Y en dicha cueva había dos cemies, hechos de piedra, pequeños, del tamaño de medio brazo, con las manos atadas, y parecía que sudaban. Los cuales cemíes estimaban mucho; y cuando no llovía, dicen que entraban allí a visitarlos y en seguida llovía. Y de dichos cemies, al uno le llamaban Boínayel y al otro Márohu".

${ }^{40}$ Ibid., pp. 39 y 40.

${ }^{41}$ Ibid., p. 45.

42 Ibid., p. 21. 
En resumen, el panorama que se desprende de la Relación de Pané es tan amplio, complejo y falto de una organización conceptual que revela una vez más el fracaso de cualquier intento por contener el "desorden" que se muestra ante los ojos de los europeos. Por supuesto que no es nuestra intención definir el sistema religioso de los taínos como "primitivo" o "simple" y, por lo tanto, como conceptualmente caótico. De hecho, la percepción del desorden de los sistemas religiosos indígenas constituye una estrategia retórica necesaria para juzgar una forma de religiosidad que la cristiandad quiere dominar.

\section{HACIA UN MONOTEÍSMO TAÍNO}

Debido al hecho de que la irreductible diversidad de los cemíes parece demasiado peligrosa para ser comparada con la noción antigua de divinidad, la Relación trata de proponer, aunque de manera discreta, otra forma de interpretación: es decir, la búsqueda de las huellas de un proto-monoteísmo: "Creen que está en el cielo y es inmortal, y que nadie puede verlo, y que tiene madre, mas no tiene principio, ya éste llaman Yúcahu Bagua Maórocoti, y a su madre llaman Atabey, Yermao, Guacar, Apito y Zuimaco, que son cinco nombres". ${ }^{43}$ Este pasaje revela que la única posibilidad que le quedó a Pané fue determinar (a pesar de las formas y las supersticiones particulares de las veneraciones relacionadas con estos desconcertantes cemíes) si los taínos tenían, por lo menos, algún tipo de conocimiento de Dios, aunque, por supuesto, primitivo e imperfecto. De acuerdo con la disposición positiva del Almirante, Pané parece admitir que los indígenas (a pesar del hecho de que, al igual que todos los paganos, parecían adorar ídolos) tenían la misma necesidad natural de conocer a Dios, y por lo tanto de reconocer la inmortalidad del cielo. Estos pocos elementos, presenta-

43 Pané, Relación..., p. 21. La cita en italiano es la siguiente: "Tengono, che sia come in cielo immortale, e che alcun non possa vederlo, et che ha madre, et ch'ei non habbia principio, et questo chiamano Iocabuuague Maorocon, et sua madre chiamano Atabei, Iermaoguacar, Apito et Zuimaco, che son cinque nomi", en Pané, Le antichità..., p. 116. 
dos como análogos, parecen suficientes para evitar la confrontación de la diferencia religiosa y cultural.

No obstante, la operación se desarrolla en un nivel superficial y encuentra sólo similitudes básicas entre las supuestas creencias indígenas y la verdad del cristianismo; similitudes justificadas, por supuesto, en la falta de racionalidad de los indígenas. No es posible aquí detenernos en el análisis de la efectiva realidad y naturaleza de este "ser supremo" de los taínos; sin embargo, es preciso señalar que lo que tendría que llamar la atención de los observadores cristianos es el hecho de que su invisibilidad parece colocarlo con facilidad en la categoría histórico-religiosa de los "creadores ociosos", más que en la categoría de las deidades de tipo monoteísta. ${ }^{44} \mathrm{~A}$ pesar de estas contradicciones, Pané procede en este incierto camino interpretativo. Después del fracaso de la búsqueda protopoliteísta, el fraile tampoco parece capaz de dar vida a un coherente proceso de transformación "teológica"; ni siquiera parece preparado para identificar la presencia de un verdadero Dios creador, eterno y omnisciente, entre los taínos. Sin embargo, su débil tentativa interpretativa logra, al menos, seleccionar el material etnográfico suficiente para abrir el camino de la "invención" de un proto-monoteísmo taíno.

Como ya hemos señalado, la Relación de Pané originó una cadena de referencias intertextuales que marcó de forma decisiva la primera etapa del debate sobre la religiosidad indígena, anticipando las necesidades hermenéuticas de la segunda generación de cronistas. Observamos, pues, la recuperación del texto de Pané por parte de Anglería y de Las Casas, no con la intención de reconstruir el camino filológico del manuscrito original, sino para observar las huellas de una intervención consciente de ambos cronistas.

${ }^{44}$ El estudio clásico sobre los "seres supremos" en la historia de las religiones es Raffaele Pettazzoni, The All-KnowingGod. Researches into Early Religion and Culture, Londres, Methuen, 1956. Sobre este tema, véanse también las reflexiones de Pierre Duviols, "La divinité supreme des Taíno selon F.R. Pané, P. Mártir et F. Bartolomé de las Casas", en Pietro Martire d'Angbiera nella storia en ella cultura [Secondo convegno internazionale di studiamericanistici, GénovaArona, 16-19 ottobre 1978], Génova, Associazione Italiana Studi Americanistici, 1980, pp. 507-510. 
Comenzamos con el paso de Anglería que, como ya se ha señalado, tradujo al latín el texto original de Pané en el libro IX de su primera Década: "Pues creen que los zemes son mensajeros de Él que confiesan que es único, infinito, omnipotente e invisible. Cada régulo tiene su zeme, a quien venera. Sus antepasados pusieron al Dios Eterno del cielo estos dos nombres: Iocaúoa, Guamaónocon.”45

Esta intervención de Anglería constituye una corrección antes que una traducción de las afirmaciones del jerónimo. Según Anglería, después de haber vivido con los indígenas por muchos años, los europeos por fin se dieron cuenta de cuál era la verdadera naturaleza de los cemíes, que Pané no había sido capaz de comprender. En primer lugar, el indefinido "ser supremo" de la Relación se convierte, en el pensamiento de Anglería, en un Dios único, omnipotente e invisible (unicum fine carentem omnipotent em invisibilemque), en una deidad celestial y eterna (coelesti numini aeterno). Claro está que esta primera intervención de Anglería parece de alguna forma previsible, casi como una consecuencia necesaria del imperfecto razonamiento de Pané; más sorprendente es, sin embargo, el invento original de Anglería, que presenta un espacio "cristiano" también para los múltiples cemíes que se encuentran en la obra de Pané y que son ahora convertidos en mensajeros de Dios, como para establecer una especie de "angelología" taína.

En tanto, fray Bartolomé de las Casas resume el breve pasaje inicial de Pané en el capítulo cxx del volumen I de la Apologética Historia:

La gente desta isla Española tenía cierta fe y cognoscimiento de un verdadero y solo Dios, el cual era inmortal e invisible que ninguno lo puede ver, el cual no tuvo principio, cuya morada y habitación es el cielo, y nombráronlo Yocahu Vagua Maorocoti; no sé lo que por este nombre quisieron significar, porque cuando lo pudiera bien saber, no lo avertí. A este verdadero y católico cognoscimiento de Dios ver-

45 Pedro Mártir de Anglería, Década primera, capítulo noveno en, Relación..., p. 92. El texto en latín es el siguiente: "Eius enim quem unicum fine carentem omnipotent em invisibilemque ese fatentur, intenuncios ese Zemes putant. Quisque regulus suum habet Zemen, quem colat. Coelesti numini aeterno duo haec nomina Iocaúna, Guamaónocon maiores eorum indiderunt" y está tomado de la edición integral de las ocho décadas: De Orbe novo Petri Martyris ab Angleria Mediolanensis protonotarii Cesaris senatoris decades, Cum privilegio imperiali, Compluti, apud Michaelem de Eguia, 1530. 
dadero se les mezclaron estos errores, conviene a saber: que Dios tenía madre, cuyo nombre era Atabex, y un hermano suyo Guaca, y otros desta manera. Debían de ser como gente sin guía en el camino de la verdad, antes había quien della los desviase, ofuscándoles la lumbre de la razón natural que pudiera guiallos. ${ }^{46}$

La transformación teológica, ya iniciada por Anglería, asume en el texto de Las Casas sus proporciones definitivas. Este "ser supremo", descrito de forma vacilante por Pané, se transforma aquí en el signo del "verdadero y católico cognoscimiento de Dios verdadero". Las Casas corrige el insatisfactorio modelo teológico de Pané y lleva a los "errores" idolátricos de los indígenas ("ique Dios tenía madre!") dentro de un modelo interpretativo más sólido: los indígenas tienen por fin una "guía en el camino de la verdad".

\section{DeIDADES, ÍDOlOS Y CUERPOS: El FRACASO DE PANÉ}

El proyecto de construcción del monoteísmo taíno invalida la consistencia etnográfica del material recogido por Pané: los cemíes no son más que vagas e incorrectas formas de conocimiento del verdadero Dios. ¿Qué elementos de la Relación de Pané, por lo tanto, tienen todavía alguna utilidad para la historia de las religiones? Si la búsqueda del "monoteísmo" es conceptualmente equivocada (en aras de construir una disciplina laica y plural), también lo es la de un "politeísmo" taíno (que, de hecho, dura tan sólo un instante en el proyecto de Pané). Paradójicamente, el fracaso hermenéutico de la interpretación del fraile nos ayuda a localizar un camino de acceso para fundamentar un análisis más acertado de la religión indígena.

Éste no es el espacio apto para recorrer detenidamente dicho camino, sin embargo, podemos señalar algunos problemas teóricos que aún refrenan una historia de las religiones vinculada a categorías producidas en el Viejo Mundo. Creemos, pues, que una genealogía de la historia de las religiones pueda desarrollarse plenamente a través de esta "lección americana", útil para mejorar la comprensión de los fenómenos plurales que ésta pretendería observar.

${ }^{46}$ Las Casas, op. cit., p. 416. 
El historiador de las religiones tendrá que empezar, en primer lugar, desde la admisión de la presencia difundida de los cemíes en cualquier lugar, de su capacidad de romper las barreras entre los reinos de la naturaleza e incluso de superar los límites entre el contexto mundano y lo trascendente. En esta perspectiva, la comparación con la religión taína indica al observador occidental, como es esencial en el análisis de las religiones indígenas, abandonar un punto de vista exclusivamente antropocéntrico. Al mismo tiempo, la noción de "culto" como forma de relación sagrada entre el oficiante y el ser adorado no es eficaz para describir las relaciones entre hombres y cemíes, que ya se había presentado de difícil comprensión para Colón cuando, en busca de huellas de oraciones taínas, parecía haber recogido sólo respuestas negativas por parte de los indígenas.

Observemos, pues, otro pasaje revelador de la obra de Pané. En el capítulo XIX de la Relación, el fraile nos habla de la construcción de cemíes de madera. En este fragmento resulta claro que la realidad sagrada descrita por el jerónimo no tiene nada que ver con una deidad (ya sea monoteísta o politeísta), sino antes bien con seres extra-humanos con los que es necesario establecer una forma de relación dialógica:

Los de madera se hacen de este modo: cuando alguno va de camino dice que ve un árbol, el cual mueve la raíz; y el hombre con gran miedo se detiene y le pregunta quién es. Y él le responde: "Llámame a un behique y él te dirá quién soy". Y aquel hombre, ido al susodicho médico, le dice lo que ha visto. Y el hechicero o brujo corre en seguida a ver el árbol de que el otro le ha hablado, se sienta junto a él, y le hace la cohoba, como antes hemos dicho en la historia de los cuatro hermanos. Hecha la cohoba, se pone de pie, y le dice todos sus títulos, como si fueran de un gran señor, y le pregunta: "Dime quién eres, y qué haces aquí, y qué quieres de mí y por qué me has hecho llamar. Dime si quieres que te corte, o si quieres venir conmigo, y cómo quieres que te lleve, que yo te construiré una casa con una heredad". Entonces aquel árbol o cemí, hecho ídolo o diablo, le responde diciéndole la forma en que quiere que lo haga. Y él lo corta y lo hace del modo que le ha ordenado; le fabrica su casa con heredad, y muchas veces al año le hace la cohoba. ${ }^{47}$

47 Pané, Relación..., p. 41. La cita en italiano es la siguiente: "Quelli di sasso si fanno in questo modo. Quando alcuno và per viaggio, dice, che vede alcuno albero; il qual muove la radice: et 
En sentido estricto, por lo tanto, el behique y el cemí negocian las etapas del proceso que conduce a la construcción del cuerpo del ser extra-humano (paradójicamente, nos encontramos con algo similar a los procesos idolátricos descritos en el contexto del Antiguo Testamento) a través del ritual de la coboba. Gracias a la acción de los mediadores adecuados se puede revelar a los hombres la naturaleza compleja de los cemíes y con ellos se pueden entablar las relaciones correctas (biográficas, familiares, políticas, cósmicas, etc.). De hecho, los taínos construyen con los cemíes una red de relaciones sociales que le otorga sentido a su realidad. ${ }^{48}$

En conclusión, es posible notar cómo la falta de comunicación entre los observadores europeos y el mundo indígena se produce en la intersección entre los diferentes usos de tres conceptos importantes: dioses, ídolos y cuerpos. Esta intersección revela, pues, la existencia de dos cosmovisiones alternativas. Por un lado, en la cosmovisión cristiana, la relación de los cuerpos (humanos) con la dimensión divina se basa en una comunicación "vertical", que se concreta en la veneración de un ser supremo. En este sentido, la negación de la unidad de este ser produce la particular forma de idolatría que es el politeísmo. No obstante, la ruptura de las jerarquías del orden cristiano se puede producir de otro modo, es decir, no sólo a través de la multiplicación excesiva de los seres adorados, sino también en una ruptura horizontal de la relación natural entre los hombres y Dios. Se realiza así aquella forma de error que se manifiesta en la veneración de la naturaleza: ésta representa, al mismo tiempo, una disminución de lo divino

l'huomo con gran paura si ferma et gli domanda, chi egli sia. Et ei risponde, Io mi chiamo Bihuitihu, et esso ti dirà, chi io sia. Et quell'huomo, andato al sopradetto medico, gli dice quello, che ha veduto: et il fattucchiero, o stregone corre subito a veder l'albero, di cui l'altro gli ha detto; et si mette a sedergli appresso; et gli fa Cohoba, come di sopra habbiam detto nella Historia de' quattro fratellli. Fatta la Coboba, si leva su in piedi, et gli dice tutti i suoi titoli, come di un gran Signore: et gli dimanda, Dimmi, chi tu sei, et che fai qui, et ciò che vuoi da me, et perche m'hai fatto chiamare. Dimmi, se vuoi che ti tagli, o se vuoi venir meco, et come vuoi, che io ti porti, che io ti fabricherò una casa con una possessione. Allhor quell'albero, o Cemi, fatto Idolo, o Diavolo, gli risponde, dicendogli la forma, nella quale vuol che lo faccia. Et egli lo taglia, et lo fa nel modo che gli ha ordinato; gli fabbrica la sua casa con possessione, et molte volte nell'anno gli fa la Cohoba", en Pané, Le antichità..., pp. 136 y 137.

${ }^{48}$ Oliver, op. cit., p. 70. 
en el contexto mundano y una amenaza a la centralidad del hombre en la creación. En la cosmovisión taína, sin embargo, esta doble ruptura se expresa positivamente en la pluralidad de cuerpos que poseen su propia agency, es decir, en la construcción de un cosmos intersubjetivo en el cual una multiplicidad de actores sociales construye un espacio complejo de relaciones. ${ }^{49}$ Por lo tanto, es evidente que, fracasada la posibilidad de describir a través de los dioses a esta inaudita estructura religiosa, el observador europeo sólo puede neutralizar su carga peligrosa a través de la noción de "ídolo", que reproduce el lenguaje excluyente de la tradición cristiana a lo largo del siglo Xvi. Por ende, la obra de Pané muestra cómo el carácter escandaloso de los cuerpos taínos representa el límite de la capacidad hermenéutica de los modelos conceptuales europeos frente a la alteridad religiosa indígena.

Recibido: 6 de agosto, 2013. Aceptado: 4 de noviembre, 2013.

\section{FUENTES}

Adorno, Rolena, "Reconsidering Colonial Discourse for Sixteenth and Seventeenth Century Spanish America", en Latin American Research Review, vol. 28, núm. 3, 1993, pp. 135-145.

Anglería, Pedro Mártir de, De Orbe novo Petri Martyrisab Angleria Medio lanensis protonotarii Cesaris senatoris decades, Cum privilegio imperiali, Compluti, apud Michaelem de Eguia, 1530.

BelFRAge, CEDRIC, My Master Columbus, Doubleday, Nueva York, 1961.

${ }^{49}$ Kenneth Morrison, "The Cosmos as Inter-subjective. Native American other-than-human persons", en Graham Harvey [ed.], Indigenous Religions: A Companion, Londres, Cassell, 2000, pp. 23-36. 
SERGIO BOTTA

Bernand, Carmen y Serge Gruzinski, De l'idolâtrie: une archéologie des sciences religieuses, París, Editions du Seuil, 1988.

Borgeaud, Philippe, Aux origines de l'bistoire des religions, París, Seuil, 2004.

BotTA, SERGIO, "El politeísmo como sistema de traducción. La obra misionera de Toribio de Benavente Motolinía frente a la alteridad religiosa de la Nueva España", en Guaraguao. Revista de Cultura Latinoamericana, vol. 28, núm. 12, 2008, pp. 9-26.

, "Towards a Missionary Theory of Polytheism: The Franciscans in the Face of the Indigenous Religions of New Spain", en Id., Manufacturing Otherness. Missions and Indigenous Cultures in Latin America, Newcastle Upon Thyne, Cambridge Scholars Press, 2013, pp. 1-26.

, La nudità degli altri. Storia delle religioni, sguardo europeo, corpi indigeni, Roma, Bulzoni, 2013.

Bourdieu, PIERRE, Esquisse d'une théorie de la pratique précédé de Trois études d'ethnologie kabyle, Génova, Droz, 1972.

Colombo, Fernando, Historie del S.D. Fernando Colombo; Nelle quali s'ba particolare, et vera relazione della vita, et de' fatti dell'Ammiraglio D. Christophoro Colombo, suo padre..., trad. de S. Alfonso Ulloa, Venecia, Francesco de' Franceschi Sanese, 1571.

Colón, CRISTóbal, Textos y documentos completos, Consuelo Varela y Juan Gil [eds.], $2^{\mathrm{a}}$ ed., Madrid, Alianza Editorial, 1992.

Duviols, PierRe, "La divinité supreme des Taíno selon F. R. Pané, P. Mártir et F. Bartolomé de las Casas", en Pietro Martire d'Anghiera nella storia en ella cultura [Secondo convegno internazionale di studi americanistici, Genova-Arona, 1619 ottobre 1978], Génova, Associazione Italiana Studi Americanistici, 1980, pp. 507-510.

Gerbi, Antonello, La natura delle Indie Nove: da Cristoforo Colombo a Gonzalo Fernández de Oviedo, Milán-Nápoles, Ricciardi, 1975.

Giddens, Anthony, Central Problems in Social Theory: Actions, Structure and Contradiction in Social Analysis, Berkeley, University of California Press, 1992. 
Gliozzi, Giuliano, "The Apostles in the New World: Monotheism and Idolatry between Revelation and Fetishism", en The Inconceivable Polytheism: Studies in Religious Historiography, Francis Schmidt [ed.], Londres-París-Nueva York, Harwood Academic Publishers, 1987 (History \& Anthropology, 3), pp. 123-148.

Greenblatt, Stephen, Marvellous Possessions: The Wonder of the New World, Oxford, Oxford University Press, 1991.

HANKE, Lewis, "The Dawn of Conscience in America: Spanish Experiments and Experiences with Indians in the New World", en Proceedings of the American Philosophical Society, vol. 107, núm. 2, 1963.

Hulme, Peter, Colonial Encounters: Europe and the Native Caribbean, 14921797, Londres, Routledge 1986.

KeEgan, Wiluam F., The People Who Discovered Columbus: The Prehistory of the Bahamas, Gainesville, University Press of Florida, 1992.

, Taino Indian Myth and Practice: the Arrival of the Stranger King, Gainesville, University Press of Florida, 2007.

las Casas, Bartolomé de, Apologética Historia, J. Pérez de Tudela Bueso [ed.], Madrid, Atlas, 1958.

Laurencich Minelui, Laura, "Fra' Ramón Pané e la fortuna della sua opera sulla religione precolombiana dell'Hispaniola", en Rivista di Storia e Letteratura Religiosa, vol. XXVI, núm. 2, 1990, pp. 229-241.

,"Diffusione e censura nell'Italia cinquecentesca dell'opea di Fra' Ramón Pané", en L'Universo, núm. 1, 1991 (Atti del simposio “Gli indios di Hispaniola e la prima colonizzazione europea in America"), pp. 60-67.

MacCormack, Sabine, "Gods, Demons, and Idols in the Andes", en Journal of the History of Ideas, núm. 67, 2006, pp. 623-647.

Mignolo, Walter D., "Colonial and Postcolonial Discourse: Cultural Critique or Academic Colonialism?", en Latin American Research Review, vol. 28, núm. 3, 1993, pp. 120-134.

Morrison, Kenneth, "The Cosmos as Inter-subjective. Native American otherthan-human persons", en Graham Harvey [ed.], Indigenous Religions: A Companion, Londres, Cassell, 2000, pp. 23-36. 
SERGIO BOTTA

OuIver, José R., Caciques and Cemi Idols. The Web Spun by Taíno Rulers between Hispaniola and Puerto Rico, Tuscaloosa, University Of Alabama Press, 2009.

PANÉ, RAMón, Relación acerca de las antigüedades de los Indios (nueva versión con notas, mapa y apéndices), José Juan Arrom [ed.], México, Siglo XxI, 1974. , Le antichità degli indiani, intr., notas y glosario de Roberta Pieraccioli y Maurizio Rippa Bonati, Cinisello Balsamo, Milán, Edizioni Paoline, 1992.

Parker, Charles H., Global Interactions in the Early Modern Age, Cambridge, Cambridge University Press, 2010.

Pettazzoni, Raffaele, The All-Knowing God. Researches into Early Religion and Culture, Londres, Methuen, 1956.

Pieraccioli, RoberTa, Rippa Bonati, Maurizio, "Introduzione", en Ramón Pané, Le antichità degli indiani, Cinisello Balsamo, Milán, Edizioni Paoline, 1992, pp. 7-74.

Rouse, IRving, The Tainos: Rise and Decline of the People who greeted Columbus, New Haven, Yale University Press, 1992.

SAmonÀ, Giuseppe A., "Linsaisissable religion des Taïnos. Esquisse d'anthropologie historique", en Journal de la société des américanistes, vol. 89, núm. 2, 2003, pp. 7-66.

Schmid, Francis, Polytheisms: Degeneration or Progress? en Id. [ed.] The Inconceivable Polytheism, Londres/París/Nueva York, Chur-Harwood, 1987 (History and Anthropology, 3), pp. 9-60.

Sheehan, Jonathan, "Thinking about Idols in Early Modern Europe", en Journal of the History of Ideas, vol. 67, núm. 4, 2006, pp. 561-570.

Strenski, Ivan, Thinking about Religion. An Historical Introduction to Theories of Religion, Oxford, Blackwell, 2006.

Stroumsa, Guy G., A New Science. The Discovery of Religion in the Age of Reason, Cambridge-Londres, Harvard University Press, 2010.

Todorov, Tzvetan, La conquête de l'Amérique. La question de l'autre, París, Éditions du Seuil, 1982. 
, Nous et les autres. La réflexion française sur la diversité bumaine, París, Éditions du Seuil, 1989.

Zamora, Margarita, Reading Columbus, Berkeley-Los Ángeles, University of California Press, 1993. 